How to cite: Magyari-Sáska, Zs., Dombay, Șt. (2020) Seasons' Shifts in Some Depressions of the Eastern Carpathians, Based on Daily Temperature Analysis. 2020 "Air and Water - Components of the Environment" Conference Proceedings, Cluj-Napoca, Romania, p. 213-222, DOI: 10.24193/AWC2020_20.

\title{
SEASONS' SHIFTS IN SOME DEPRESSIONS OF THE EASTERN CARPATHIANS, BASED ON DAILY TEMPERATURE ANALYSIS
}

\author{
Zsolt MAGYARI-SÁSKA ${ }^{1}$, Ștefan DOMBAY $Y^{1}$
}

DOI: 10.24193/AWC2020_20

\begin{abstract}
The Eastern Carpathians depressions were always considered as the cold corner of Romania having the lowest temperatures. With all these in the past several years in these basis where the apples and potatoes were the most common cultures, now not only maize, cherry and tomatoes are cultivated but also grape and apricot is present. Our research wanted to investigate if it's about changing in seasons length as it's present in everyday talk (ex. there's no more spring) and if it's a possibly lasting situation or not. Based on daily minimum, maximum and mean temperature values, applying $\mathrm{K}$-means clustering for automatic season detection and trend analysis we found that these depressions are affected by global climate change, but this not affects the presence of the four classic season for continental climate. The seasons are notable but there are changes in how they can be characterized. The most notable result in our current research is that there are significant trends in summers' minimum, maximum and mean temperatures for all these depressions. The year 2006 could be considered as breaking year for daily mean temperatures as the obtained two periods has a significant difference regarding the daily mean temperature value with an absolute difference between $1.1-1.3$ degree Celsius.
\end{abstract}

Keywords: Romania, Eastern Carpathian depressions, changing seasons, global climate change, clustering

\section{INTRODUCTION}

Changes in season's start, length and characteristics is a worldwide a noticed phenomenon. Even the astronomical seasons are the same, the meteorological seasons which affects nature are in constant change (Thompson, 2009). This change has different manifestations, in some places the fall seams to disappear, in other location the spring is close to vanish. The winter and summer temperatures are more and more similar, altogether with the increasing frequency of extreme values (Magyari-Sáska, 2017). The importance of the subject is emphasized that in addition to the scientific world, many non-governmental and professional organizations, which are not directly connected to climate, are concerned on effects of temperature and season changes and publish articles on the issue.

\footnotetext{
${ }^{1}$ Babeș-Bolyai University, Faculty of Geography, Gheorgheni Extension, 535500 Gheorgheni, Grădina Csiky, zsmagyari@gmail.com dombay.istvan@gmail.com
} 
These changes are present worldwide (Meresa et. Al, 2017) also in Carpathians (Melo et al., 2013) and in Romania (Micu et al, 2014; Croitoru and Piticar, 2013). The Eastern Carpathians' (the Oriental Carpathians) studied depressions are North to South oriented, with average decreasing altitudes (Giurgeu, $800 \mathrm{~m}$; Ciuc, $700 \mathrm{~m}$; Brașov, $600 \mathrm{~m}$ ) (badea, 1983), have been special locations in Romania in terms of temperature (Fig. 1). These were the so-called cold corners of the country with a significant population.

In these locations where several decades ago the apples and potatoes were the most common cultures, now not only maize, cherry and tomatoes are cultivated but also grape and apricot is present. In the past years the nature was perturbed by the warm autumn and mild winter, several plant starting to sprout in November and even December. The upcoming frost destroy these buds and weakens the plants. Our research studies the meteorological base of these changes using daily and data trying to show up whether these changes has a clear trend or are the result of an unsteady climate.

Even the changes in temperature and its effect are studied for different locations there are just several studies which targets the Eastern Carpathian basins (Petres et al, 2017; Magyari-Sáska, 2006).

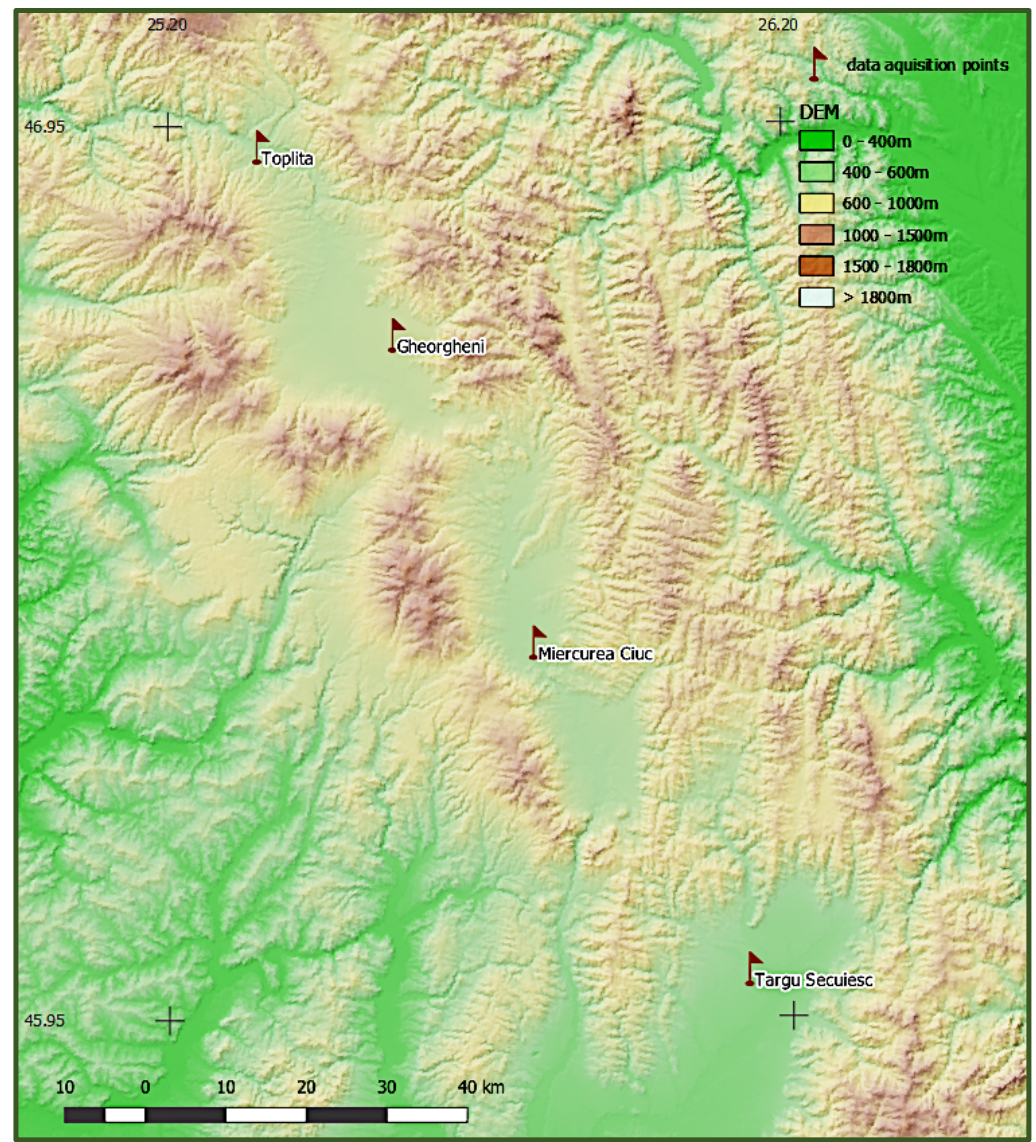

Fig. 1. Study sites with data acquisition points 


\section{METHODS AND DATA}

\subsection{Methods}

Through our research three analyzing methods are present. First of all, as we decided to work with detected seasons and to compare the results with the classical seasons temporal position and extension we needed a method for automatic detection. One of the most used method is clustering which uses the similarity between the given values and based on different functions arranges the values in a given number of clusters.

There are different types of clustering methods: connectivity based, centroid based, density based etc. which mainly differs how the notion of cluster, as group of closely related values, appears and which type of function measures the possible membership of a given value to a cluster.

$\mathrm{K}$-means clustering is one of the distance based methods which is largely used in meteorology and climate analysis starting from characterizing a situation (Gokila et al, 2015) to forecasting (Nguyen-Le et al., 217) and even for data mining (Chakraborty et al., 2012). The standard algorithm is well described by Hartigan and Wong in their article from 1979. It uses as distance function is the Euclidian distance.

From the beginning the desired cluster number $(\mathrm{k})$ should be known by the algorithm. It selects an arbitrary $\mathrm{k}$ values to became cluster centers and assigns every other value to these centers based on the minimum Euclidian distance. After all values has been assigned for each cluster a new center will be calculated as the mean value of the existing clusters. The process will be repeated till no assignment changes are detected or a given number of iteration are reached. The method can be used based a single clustering variable or based on multiple variables (Forgy, 1965; MacQueen, 1967) and by this a set of different meteorological value can be used for clustering.

Trend detection was the other method we applied, which is widely used also in recent climate investigation (Zelenkova et. al, 2018; Mudelsee, 2019). One of the most well-known and used trend analysis method is the Mann Kendall test. It detects the monotonic trend in temporally equally distributed data series. Being a nonparametric test it works well for different kind of fitted data distributions. The null hypothesis of the test is that the data does not have any monotonic trend. The MannKendall statistics is based on the signum (sign) function and calculates the sum of sign values $(-1,0$ or 1$)$ for all data pairs in the series in raising order of their appearance, having a significance table of its own.

The check whether there are significant changes in means of two data series a Welch t-test can be used which is a generalization of Student t-test, because it doesn't imposes to have a significantly not different data series for the variance (Welch, 1947).

\subsection{Data and software}

The analyzed data was obtained from the POWER Project Data Sets, which includes meteorological data sets from NASA research. The period covered by this data set is between 1982 and 2019 with no lacks of data. For our research we used 
three temperature data set, the daily mean, minimum and maximum values. The data values were in CSV format easily operable in various analysis software.

The whole analysis was made in $\mathrm{R}$ statistical environment which offers a great number of extension packages for different kind of specialized research. For us just the Kendall external package was necessary for the trend test as the K-means clustering method is part of the base $\mathrm{R}$ package as it's the Welch t-test too.

\section{RESULTS AND DISCUSSION}

We started with using K-means clustering method for different temperature series setting four classes corresponding to the four seasons. As the clustering algorithm could not make differences between spring's and autumn's mild temperatures we decided to use only three categories in clustering, separating them visually. Because of spring and autumn has become a single category we used the following terms for season identification: cold as for winter, warm as for summer and transitional as for spring and autumn together.
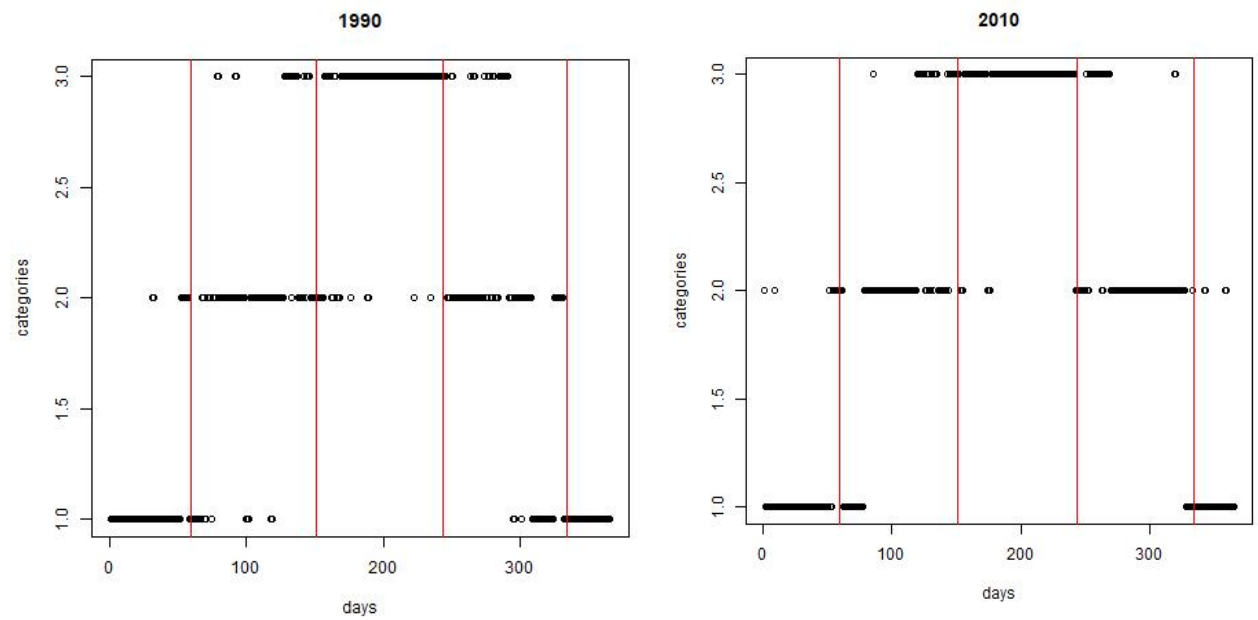

Fig. 2. K-mean based cluster analysis identifying seasons (location: Toplita, clustering variable: maximum daily temperature)

At first sight nothing strange was revealed. We could identify and characterize different kind of years in terms of temperature. In all cases all four seasons were present at their ordinary time interval with slight, normal variation as discussed below (Fig. 2). The vertical red lines mark the limits of classic seasons. With all these we tried to make some undergoing research to reveal some aspects that could explain the fact which was observed through the past years and presented in the introduction chapter.

On clustering based on the daily average temperature we have checked the evolution of seasons as number of days (ND), number of days in their 
corresponding months (NCD) and the evolution of differences between the two mentioned elements. We have found that in all cases for cold and transitional seasons there is a much better correlation between the ND and NCD values. Almost all summer days were considered warm season days (Fig. 4), and also warm days appeared in other seasons. In case of winter, spring and autumn their day number varied accordingly with cold or transitional day number (Fig. 3). No significant tendencies were detected nor in ND nor in NCD series. The appreciations are valid for all four studied locations.

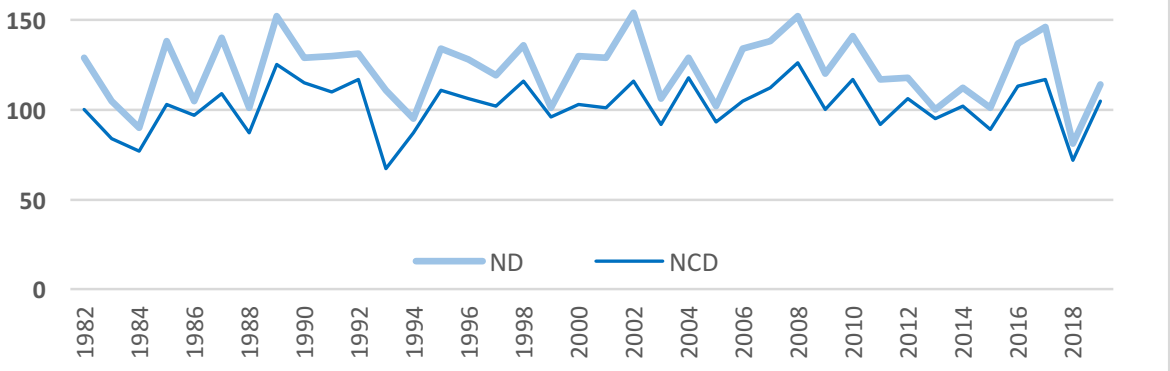

Fig. 3. Evolution of ND and NCD indicator (location: Gheorgheni, transitional season)

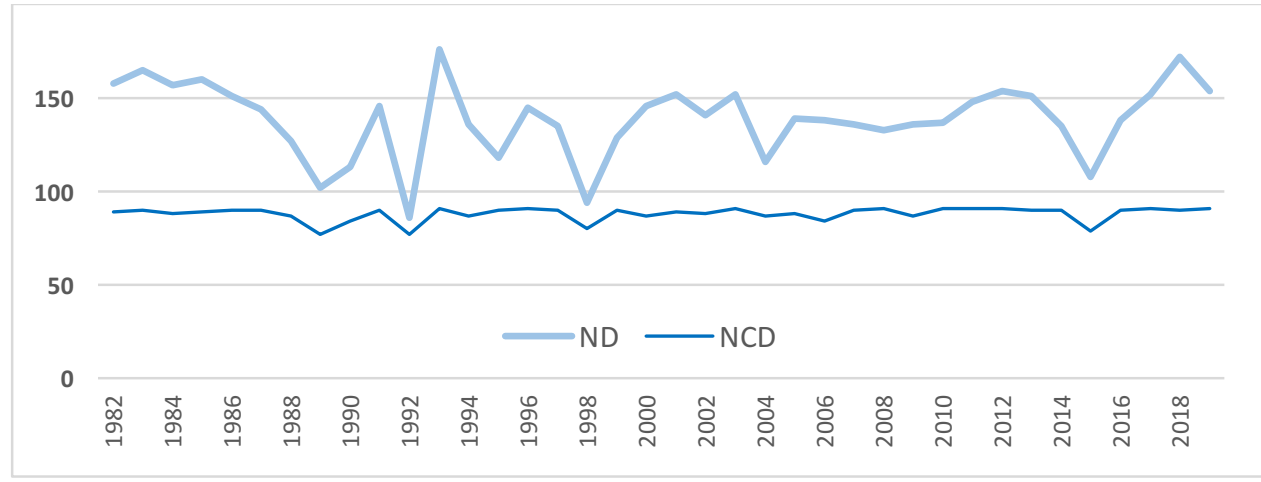

Fig. 4. Evolution of ND and NCD indicator (location: Gheorgheni, warm season)

Considering that probably not just the length of the detected periods, but the effective temperature values are responsible for the different perception of seasons, we started to analyze the trend of mean values for the detected seasons. As we make a three-way season detection based on daily mean, minimum and maximum temperatures we had three different situations.

Using Mann-Kendall statistics for trend detection we got the result summarized in table 1 . We use the $90 \%$ statistical significance level, even if for some cases $95 \%$ was also reached. These cases are also marked in the table. 
Table 1. Mann Kendall trend test applied to temperature values with their significance level

\begin{tabular}{|l|c|c|c|c|c|c|c|c|c|}
\hline Clustering variable & \multicolumn{3}{|c|}{$\mathrm{T}_{\text {MEAN }}$} & \multicolumn{3}{c|}{$\mathrm{T}_{\text {MINIMUM }}$} & \multicolumn{3}{c|}{$\mathrm{T}_{\text {MAXIMUM }}$} \\
\hline Season type & $\mathrm{C}_{\text {old }}$ & $\mathrm{T}_{\text {ransit }}$ & $\mathrm{W}_{\text {arm }}$ & $\mathrm{C}_{\text {old }}$ & $\mathrm{T}_{\text {ransit }}$ & $\mathrm{W}_{\text {arm }}$ & $\mathrm{C}_{\text {old }}$ & $\mathrm{T}_{\text {ransit }}$ & $\mathrm{W}_{\text {arm }}$ \\
\hline Toplita & & & 0.95 & & & 0.95 & 0.90 & \\
\hline Gheorgheni & & & 0.95 & & & 0.95 & 0.90 & 0.90 \\
\hline Miecurea-Ciuc & & & 0.95 & & & 0.95 & & & 0.90 \\
\hline Targu Secuiesc & & 0.90 & 0.95 & & & 0.95 & & & \\
\hline
\end{tabular}

Regarding the trend of temperature values, significant trend was observed especially for warm season disregarding whether the seasons were detected based on daily minimum, maximum or mean temperature.

The slope of the trend is not very high, it was between 3 to 5 degrees, but in a period of 10 years in the coldest basins of Romania the average of daily maximum values for the cold season will be over $1^{\circ} \mathrm{C}$ (Fig. 5).

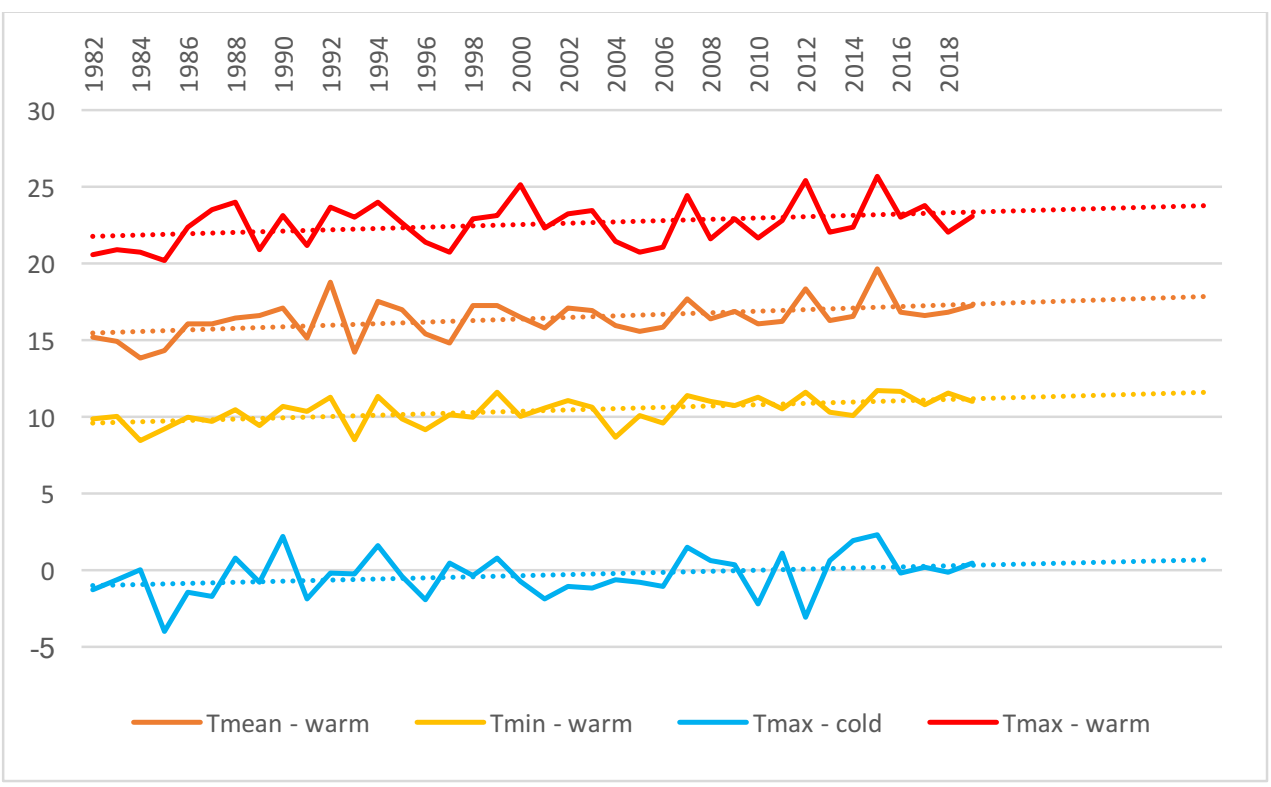

Fig. 5. Temperature values and associated trend lines for Toplita (legend: clustering variable - season)

Using the daily mean temperature as clustering variable no trend was observed in detected seasons' length as presented earlier. But in case of daily minimum temperature as clustering variable a trend was observed in season length (expressed in number of days) as shown on table 2.

This means that if we consider the daily minimum temperature - which occurs at dawn in basins - as decisional factor to decide if a day belongs to cold, warm or transitional season the there's a trend in cold and transitional season's length. 
Table 2. Mann Kendall trend test applied to detected season length with their significance level

\begin{tabular}{|l|c|c|c|c|c|c|c|c|c|}
\hline Clustering variable & \multicolumn{3}{|c|}{$\mathrm{T}_{\text {MEAN }}$} & \multicolumn{5}{c|}{$\mathrm{T}_{\text {MINIMUM }}$} & \multicolumn{3}{c|}{$\mathrm{T}_{\text {MAXIMUM }}$} \\
\hline Season type & $\mathrm{C}_{\text {old }}$ & $\mathrm{T}_{\text {ransit }}$ & $\mathrm{W}_{\text {arm }}$ & $\mathrm{C}_{\text {old }}$ & $\mathrm{T}_{\text {ransit }}$ & $\mathrm{W}_{\text {arm }}$ & $\mathrm{C}_{\text {old }}$ & $\mathrm{T}_{\text {ransit }}$ & $\mathrm{W}_{\text {arm }}$ \\
\hline Toplita & & & & 0.95 & 0.95 & & & & \\
\hline Gheorgheni & & & & 0.95 & 0.95 & & & & \\
\hline Miecurea-Ciuc & & & & 0.95 & 0.90 & & & & \\
\hline Targu Secuiesc & & & & 0.95 & 0.90 & 0.95 & & & \\
\hline
\end{tabular}

For all studied location the length of the cold season is shrinking while the length of the transitional season is slightly rising. By this we can conclude that based on daily minimum temperature the winter is on a disappearing way as it tends to take only around $15 \%$ from the whole year days (Fig. 6).

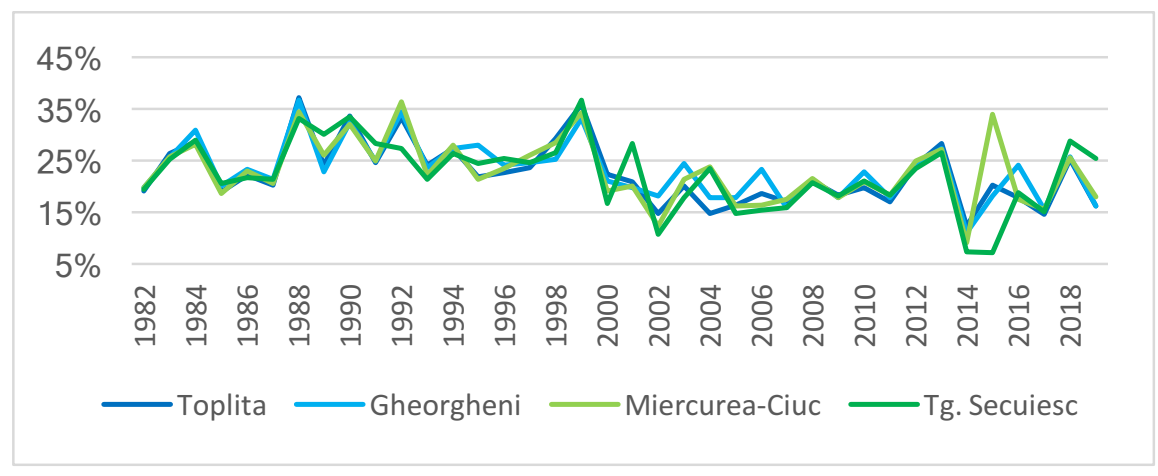

Fig. 6. Evolution of cold season share (clustering variable: daily minimum temperature)

We also wanted to study whether is a break point, and a year can be identified to divide the whole period into two with statistically significant different mean. This analysis was made for all three clustering variable and for all four locations. Using the two sample Welch t-test we determined these years as presented in table 3.

Table 3. Welch t-test detected break years with their significance (red 95\%, orange 90\%)

\begin{tabular}{|l|c|c|c|c|c|c|c|c|c|}
\hline Clustering variable & \multicolumn{3}{|c|}{$\mathrm{T}_{\text {MEAN }}$} & \multicolumn{3}{c|}{$\mathrm{T}_{\text {MINIMUM }}$} & \multicolumn{3}{c|}{$\mathrm{T}_{\text {MAXIMUM }}$} \\
\hline Season type & $\mathrm{C}_{\text {old }}$ & $\mathrm{T}_{\text {ransit }}$ & $\mathrm{W}_{\text {arm }}$ & $\mathrm{C}_{\text {old }}$ & $\mathrm{T}_{\text {ransit }}$ & $\mathrm{W}_{\text {arm }}$ & $\mathrm{C}_{\text {old }}$ & $\mathrm{T}_{\text {ransit }}$ & $\mathrm{W}_{\text {arm }}$ \\
\hline Toplita & & 1988 & 1988 & 2012 & & 2006 & $\mathbf{2 0 1 2}$ & & 1991 \\
\hline Gheorgheni & $\mathbf{2 0 1 2}$ & 1988 & 1991 & 2012 & & 2006 & $\mathbf{2 0 1 2}$ & 2010 & 1997 \\
\hline Miecurea-Ciuc & 2012 & 1988 & 1988 & & 1988 & 2006 & 2012 & 2010 & 1997 \\
\hline Targu Secuiesc & $\mathbf{2 0 1 2}$ & 1988 & 1997 & 2001 & 1988 & 2006 & 2012 & & 1997 \\
\hline
\end{tabular}

The values in cells indicates those years for which the Welch t-test performed with highest significance to mark that there's a difference between the two periods mean values. A minimum of 7-year distance was considered from both end of the 
data series. The situations when the Welch t-test could not find a break year with at least $90 \%$ significance are represented with gray cell in table 3 . In case of multiple significant break years, the table presents those with the highest significance.

We can observe that for cold season the breaking year with the highest frequency is 2012, while for the warm season the year varies based on the used clustering variable. In case when the clustering for season detection clustering was based on the daily minimum temperature the breaking year for the warm season is 2006 for all locations (Fig. 7), with a difference between mean values of $1.1-1.3^{\circ} \mathrm{C}$.

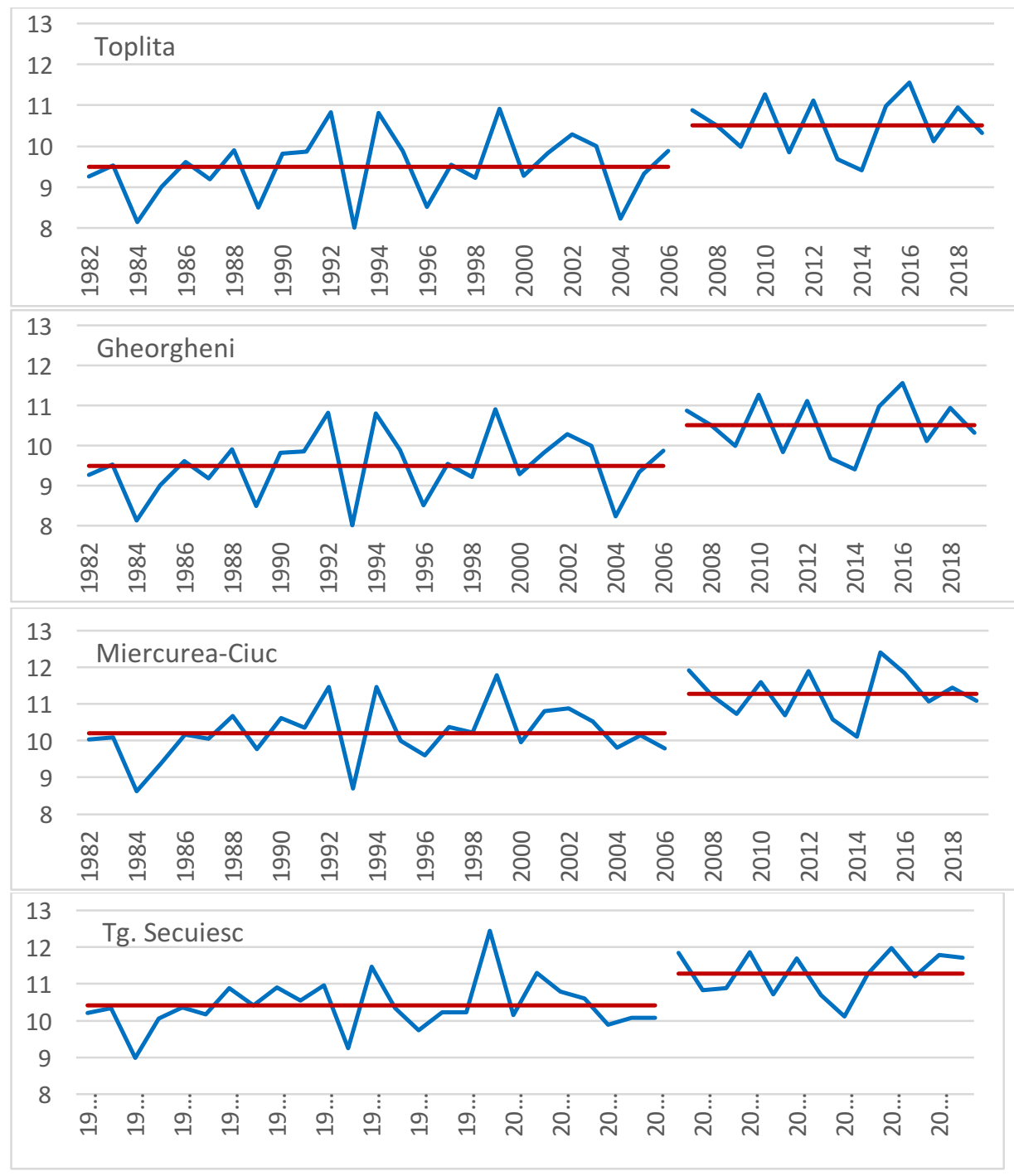

Fig. 7. Significantly different mean values of daily mean temperatures for the warm season having year 2006 as breaking point. 


\section{CONCLUSIONS}

Using a 38-year dataset with daily mean, minimum and maximum temperature data and the automatic clustering method for each year and each location representing the Eastern Carpathians' depressions, all four seasons could be identified. The temporal location of the identified seasons corresponds to their classic position. It's no reason to talk about season shift or disappearance of seasons, but the actual seasons has different characteristics that in past and that's the main reason for what in every day's life we can hear sayings that there was no spring, or there's no more real winter.

The analysis we made has concentrated on the characteristics of automatically detected seasons. The length expressed in days of these seasons even it's not equally distributed through a year, has no trend for grew or shrunken from 1982 to present day. We were using three temperature types to make the season detection, each one separately because every of them has its own importance in everyday appreciation. For example, the daily minimum corresponds to the dawn and early morning. These very low temperatures, often due to thermal inversions, represents a notable difference between depressions and plain zones. In this case a significant trend translates into an increase with $2-2.5^{\circ} \mathrm{C}$ for daily minimum, maximum and mean temperatures through a 38 year period.

Even if there's a trend for the whole studied period we could identify years which divides the period in parts with significantly different mean values. For different kind of season detection and different kind of temperatures, these years varies but for cold season for all location 2012 is the changing year, while for warm season 2006 is that year.

It should be mentioned that the four analyzed location has a similar behavior for the analysis we made. Our final conclusion is that not the shifting of seasons, but the rising trend of all temperature values and a clear rupture in the past 10-13 years which have raised the mean value of temperatures with over $1^{\circ} \mathrm{C}$, makes possible the cultivation of crops (fruits, vegetables and some ornamental plants) that were not native in Easter Carpathians basins. The global warming felt its presence even these well geographically well protected areas.

\section{REFERENCES}

1. Badea L (1983), The Geography of the Romania (into Romanian), Academiei Edit., București.

2. Chakraborty, S., Nagwani N.K., Dey, L. (2012), Weather Forecasting using incremental K-means clustering, Data Mining and knowledge engineering, 4(5), 214219

3. Croitoru A.E., Piticar A. (2013) Changes in daily extreme temperatures in the extraCarpathians regions of Romania, International Journal of Climatology, 33(8), pp. 1972001

4. Forgy, E. W. (1965). Cluster analysis of multivariate data: efficiency vs interpretability of classifications. Biometrics, 21, 768-769. 
5. Gokila, S., Ananda Kumar, K., Bharathi A., (2015), Clustering and Classification in Support of Climatology to mine Weather Data - A Review, International Journal of Computing Algorithm, 4(1)

6. Hartigan, J. A. and Wong, M. A. (1979). Algorithm AS 136: A K-means clustering algorithm. Applied Statistics, 28, 100-108. doi: 10.2307/2346830.

7. MacQueen, J. (1967). Some methods for classification and analysis of multivariate observations. In Proceedings of the Fifth Berkeley Symposium on Mathematical Statistics and Probability, eds L. M. Le Cam \& J. Neyman, 1, pp. 281-297. Berkeley, CA: University of California Press.

8. Magyari-Sáska Zs., Dombay S (2017), Changes in Europe's Temperature Extreme Values., Air and Water Components of the Environment, Conference proceedings, 77-84

9. Magyari-Sáska Zs., Haidu I. (2006), Analiza cantitativă a riscului de îngheț în bazinul superior al Mureşului (in Romanian), Geographia Technica 1(1), pp 115-20

10. Mann, H.B. (1945), Nonparametric tests against trend, Econometrica, 13, 245-259.

11. Melo M., Lapin M., Kapolková H., Pecho J., Kružicová A. (2013) Climate Trends in the Slovak Part of the Carpathians. In: Kozak J., Ostapowicz K., Bytnerowicz A., Wyżga B. (eds) The Carpathians: Integrating Nature and Society Towards Sustainability. Environmental Science and Engineering. Springer, Berlin, Heidelberg

12. Meresa, H.K., Romanowicz, R.J. \& Napiorkowski, Understanding changes and trends in projected hydroclimatic indices in selected Norwegian and Polish catchments, J.J. Acta Geophys. (2017) 65: 829. https://doi.org/10.1007/s11600-017-0062-5

13. Micu D.M., Dumiterscu A., Cheval S., Birsan M-V, (2014), Climate of the Romanian Carpathians: Variability and Trends, Springer

14. Mudelsee, M. (2019), Trend analysis of climate time series: A review of methods, Earth-Science Reviews, 190, pp. 310-322

15. Nguyen-Le, D., Yamada, T.J., Tran-Anh, D. (2017), Classification and forecast of heavy rainfall in northern Kyushu during Baiu season using weather pattern recognition, Athmospheric Science Letters, 18, pp. 324-329

16. Petres, S.; Korodi, A.; Keresztes, R.; Szep, R. (2017), Tendencies And Particularities In Thermic Inversion Episodes In The Ciuc Basin - Eastern Carpathians, Romania, Conference Proceedings, 17th International Multidisciplinary Scientific GeoConference SGEM 2017, 17(14), 445-452

17. Thompson D.J., 209, Shifts in season, Nature 457, p 391-392

18. Welch, B. L. (1947). "The generalization of "Student's" problem when several different population variances are involved". Biometrika. 34 (1-2): 28-35.

19. Zeleňáková, M., Purcz, P., Blišt’an, P., Vranayová, Z., Hlavatá, H., Diaconu, D. Constantin, \& Portela, M. Manuela. (2018). Trends in Precipitation and Temperatures in Eastern Slovakia (1962-2014). Water, 10, . doi: 10.3390/w10060727 